\title{
Sociodemographic, lifestyle and dietary correlates of dietary supplement use in a large sample of French adults: results from the NutriNet-Santé cohort study
}

\author{
Camille Pouchieu $^{1 *}$, Valentina A. Andreeva ${ }^{1}$, Sandrine Péneau ${ }^{1}$, Emmanuelle Kesse-Guyot ${ }^{1}$, \\ Camille Lassale $^{1}$, Serge Hercberg ${ }^{1,2}$ and Mathilde Touvier ${ }^{1}$ \\ ${ }^{1}$ Université Paris 13, Sorbonne Paris Cité, UREN (Nutritional Epidemiology Research Unit), Inserm (U557), Inra (U1125), \\ Cnam, SMBH Paris 13, 74 rue Marcel Cachin, F-93017 Bobigny Cedex, France \\ ${ }^{2}$ Département de Santé Publique, Hôpital Avicenne, F-93017 Bobigny Cedex, France
}

(Submitted 19 July 2012 - Final revision received 13 December 2012 - Accepted 30 January 2013 - First published online 22 February 2013)

\begin{abstract}
Information on the determinants of dietary supplement (DS) use in France is largely lacking, especially in population subgroups such as smokers. Also, little is known about the role of health professionals in DS purchases. The aim of the present study was to describe DS use along with its sociodemographic, lifestyle and dietary correlates in a large sample of French adults (age 18+years) participating in the NutriNet-Santé cohort study. Data were collected by self-administered Internet questionnaires. Food intakes were assessed by $24 \mathrm{~h}$ dietary records. Data on DS use were available for 79786 participants. Supplement users were compared with non-users by logistic regression. Current DS use at least three times/week was reported by $14.6 \%$ of men and $28.1 \%$ of women. $\mathrm{Mg}$, and vitamins $\mathrm{B}_{6}$ and $\mathrm{C}$ were the most frequently consumed nutrients. DS were prescribed or recommended by a physician in $54.9 \%$ of the cases. DS use was positively associated with knowledge of nutritional recommendations and organic product consumption, following a healthier diet and lifestyle (non-smoker, moderate leisure-time physical activity). Current smokers used less DS than did non-smokers, but their DS consumption was substantial (19.0\%) and they were more likely to self-medicate. The present study provides updated and detailed information on DS use determinants in a large French cohort, including a focus on smokers, for whom the long-term effects of DS use are poorly documented and could represent a risk. These findings pave the way for future aetiological studies.
\end{abstract}

Key words: Dietary supplements: Motivation: Health behaviour: Smoking status

Dietary supplements (DS) are defined as 'foodstuffs the purpose of which is to supplement the normal diet and which are concentrated sources of nutrients or other substances with a nutritional or physiological effect, alone or in combination, marketed in dose form [...]' (European Directive 2002/46/CE). In the USA, DS use is widespread and well documented $^{(1-4)}$. In Europe, several studies have also investigated the determinants and prevalence of DS use, and showed that DS use was lower than that in the $\mathrm{USA}^{(5-7)}$. However, such knowledge as regards the French context is largely lacking. Since health and nutrition-related behaviours may strongly vary from one country to another, it is important to conduct country-specific studies regarding DS use. Traditionally in France, DS use has not been a practice as common as in other European countries or in the USA, partly due to the underlying differences in attitudes towards diet and nutrition. The few existing French studies about DS use were based on very small samples ${ }^{(8)}$, are outdated ${ }^{(2)}$ or were restricted to specific subgroups ${ }^{(9,10)}$. In $2005^{(11)}$ and $2006^{(12)}$, DS use was assessed in nationally representative samples of the French population, but the findings of these two studies have not been disseminated internationally. In addition, they were based on a relatively small sample of subjects, thereby not allowing specific analyses on DS use in population subgroups. These studies have suggested that the proportion of DS users increased steadily over time, and also revealed several sociodemographic and lifestyle correlates of DS use, such as a higher intake of fruits and vegetables, with a lower BMI and higher levels of physical activity. If DS use is indeed associated with several sociodemographic, economic, lifestyle and dietary factors, a precise assessment of these associations and of DS users' profile is an important parameter for future aetiological studies on nutritional intake, DS use and chronic disease risk. The objectives of the present study were to

Abbreviation: DS, dietary supplement.

*Corresponding author: C. Pouchieu, email c.pouchieu@uren.smbh.univ-paris13.fr 
provide updated and detailed data on DS use and to explore sociodemographic, lifestyle and dietary correlates of DS use in the NutriNet-Santé study, which involves a large cohort of French volunteers. We also evaluated the role of physicians in the motivation for DS purchases and the proportion of self-medication, as limited information was available on this topic in France ${ }^{(13,14)}$. Finally, growing evidence of increased cancer risk exists regarding the association between tobacco smoking and the use of some DS such as $\beta$-carotene supplements ${ }^{(15-17)}$. Thus, we also described DS use (types, motivations, self-medication, etc.) according to smoking status.

\section{Methods \\ Study population}

The NutriNet-Santé study is the first Web-based, general population, prospective observational cohort study worldwide aimed at elucidating the link between nutrition and health. Specifically, it was launched in France in the spring of 2009 to evaluate the determinants of eating behaviour and the relationship between nutrition and chronic disease risk ${ }^{(18)}$. Participants were recruited by a vast multimedia campaign. Inclusion criteria pertain to residence in France, age $\geq 18$ years and access to the Internet. Registration and participation took place online using a dedicated web site (www.etudenutrinet-sante.fr). By January 2012, 102988 volunteers had completed all of the baseline questionnaires and were included in the study. Follow-up is planned for at least 10 years. The present study was approved by the International Research Board of the French Institute for Health and Medical Research (IRB Inserm no. 0000388FWA00005831) and the 'Commission Nationale de l'Informatique et des Libertés' (CNIL no. 908450 and no. 909216).

\section{Data collection}

Participants filled in self-administered, Web-based questionnaires at baseline and then regularly during the follow-up. Written informed consert was obtained from all subjects.

\section{Dietary supplement use}

The questionnaire regarding DS use was administered 2 months after inclusion. In the present study, we considered as DS both true DS and medicinal supplements (supplements considered as pharmaceutical products in France, and mainly composed of vitamins and minerals). Participants were asked whether they were currently taking any supplement at least $3 \mathrm{~d} /$ week at the time of the DS questionnaire ('current DS users'), and were also asked to specify the type of DS using a list of thirty-four different nutrients and substances. They were also asked whether they took any DS in the past 12 months (at least once). The frequency and duration of use for each DS was assessed, thereby permitting the calculation of the average number of days of use in the last 12 months and the overall duration of use. The questionnaire also included assessment of the circumstances and motivations for DS use, the physician's role in DS purchases and the seasonality of DS use.

\section{Sociodemographic, lifestyle and behavioural data}

At inclusion, self-administered questionnaires collected data on sociodemographic and lifestyle characteristics, including age, sex, marital status, number of children, education, occupation, smoking status, anthropometry, following a restrictive diet, pregnancy and menopause in women, and leisure-time physical activity (estimated with the International Physical Activity Questionnaire $\left.{ }^{(19)}\right)$. The instruments were tested against traditional assessment methods (paper or interview by a health professional) ${ }^{(20-22)}$.

\section{Dietary data}

At inclusion, participants were asked to complete three non-consecutive, self-administered, Web-based $24 \mathrm{~h}$ dietary records, the days for which were randomly assigned during a 2 -week period ( $2 \mathrm{~d}$ during the week and $1 \mathrm{~d}$ during the weekend). Participants were included in the NutriNet-Santé cohort if they provided at least one $24 \mathrm{~h}$ dietary record at baseline. All foods and beverages consumed at breakfast, lunch or dinner were recorded. For foods with potentially high nutrient variability, participants were also asked to provide the brand name. Participants estimated the portion size for each reported food and beverage item using validated photographs ${ }^{\text {(23) }}$ A comparison of the Web-based dietary assessment with a traditional dietitian's interview showed good agreement between the two methods ${ }^{(21)}$. Daily dietary intakes of various nutrients were calculated using the 'NutriNet-Santé food composition table, which included more than 2500 different foods.

Knowledge of official nutritional recommendations as provided in the 'French National Nutrition and Health Program, (24) was also assessed. It pertained to recommendations regarding five main food groups (fruits and vegetables, dairy products, meat, fish and starchy food). Finally, a specific questionnaire was used to assess the opinion and behaviour of the participants towards organic food consumption.

\section{Statistical analyses}

All participants of the cohort who were included before January 2012 and who answered the DS questionnaire were included in the analyses ( $n$ 79 786). Proportions of DS users (current users and users of at least one supplement during the past 12 months), types of DS consumed by current users, frequency, circumstances, motivations and seasonality of use were described in the full sample and also by smoking status (current, former and never smokers).

OR and 95\% CI were calculated by age- and sex-adjusted logistic regression analyses comparing DS users (i.e. those who reported DS use at least once during the past 12 months) and non-users regarding their sociodemographic characteristics (age, sex, geographical region, marital status, number of children, education and occupation), lifestyle and behavioural factors (smoking status, BMI, current practice of 
a restrictive diet, leisure-time physical activity, pregnancy, self-perceived emotional state and physical pain, knowledge of official nutritional recommendations and organic food consumption). $P$ values from the Wald test were provided. Tests for linear trend were performed using the ordinal score on categories of each variable.

Only subjects who provided three dietary records at baseline and who were normo-energy reporters according to the Goldberg criterion ${ }^{(25)}$ were included in the analysis relative to dietary data. The mean daily intakes of twenty-three different food groups, dietary micro- and macronutrients, energy, dietary fibre and alcohol were compared by logistic regression analyses between DS users and non-users after adjustment for sex, age and energy intake. The proportion of subjects with reported intake below the estimated average requirement for the French population ${ }^{(26)}$ was estimated for each nutrient by sex. It was established that, at the population level, this proportion represents an unbiased estimate of the proportion of subjects whose intake is below their respective requirements, also called 'prevalence of inadequacy ${ }^{\text {(27) }}$. When an individual has intake below his/her requirement, this may lead to a risk of chronic insufficient intake, and possibly, deficiency. The measurement error model proposed by the National Research Council $^{(28)}$ and developed by Nusser et al. ${ }^{(29)}$ was applied to the observed daily dietary intake, in order to remove the effects of day-to-day intake variability. The prevalence of inadequate dietary nutrient intake was then compared between DS users and non-users in men and women by logistic regressions adjusted for age and energy intake.

A $P$ value $<0.05$ was considered as significant in all statistical tests. All tests were two-sided. All analyses were carried out with SAS software (release 9.1; SAS Institute, Inc.)

\section{Results}

Proportion of dietary supplement users, type, motivations and circumstances of dietary supplement use

The average age of the participants ( $n$ 79786) was $45 \cdot 2$ (SD 14.5) years and women constituted $76 \%$ of the sample. Among the study population, $32.4 \%$ were executives or had an intellectual profession, 30.0\% were employees, $25.9 \%$ had an intermediate profession, 5.3\% were unemployed, $3.2 \%$ were manual workers, $2 \cdot 8 \%$ were self-employed and $0.4 \%$ were farmers. The proportions of overweight (not including obesity) and obese subjects were 22 and 10\%, respectively.

DS use among men and women is presented in Table 1. About $41 \%$ of the subjects reported the use of at least one DS during the 12 months preceding the survey. About $25 \%$ of the respondents were current users (DS use at least $3 \mathrm{~d}$ / week at the time of the DS questionnaire: $28.1 \%$ in women and $14.6 \%$ in men). In current DS users, $\mathrm{Mg}$, vitamin $\mathrm{B}_{6}$, vitamin $\mathrm{C}, \mathrm{Zn}$ and Fe were the most frequently used nutrients, whereas $n$-3 fatty acids and herbal supplement use were relatively low (Table 1 ).

Motivations, circumstances of DS purchases and seasonality are presented in Table 2 . The main reasons for DS use were to 'overcome tiredness' and to 'stay healthy', whereas 'compensating for an inadequate dietary intake' was quoted by only $5 \cdot 4 \%$ of the DS users. DS were mainly purchased with a prescription, following medical advice or a recommendation by a pharmacist. DS use was increased during the autumn and winter months.

In the last 12 months, 61359 DS were declared by the participants. Among them, $41.0 \%$ were used for less than 1 year, $22 \cdot 1 \%$ were used $1-2$ years, $19 \cdot 3 \%$ were used over $3-5$ years, $9 \cdot 8 \%$ were used 5-10 years and $7 \cdot 8 \%$ were used for more than 10 years. In the last 12 months, the average duration of DS use was 94.7 (SE 108) d (data not shown).

\section{Sociodemographic, lifestyle and behavioural correlates of dietary supplement use}

When compared with non-users, DS users were more likely to be women, older, more educated, better employed and more physically active (Table 3). DS use decreased with the number of children. Users were more likely to be non-smokers, to have a lower BMI and to follow a restrictive diet. Women who took supplements were more likely to be pregnant or postmenopausal. Users were more likely to report emotional problems, physical pain, increased familiarity with official nutritional recommendations (recommendations of the French National Nutrition and Health Program) and organic food consumption.

\section{Dietary supplement use according to smoking status}

In the study population, $17 \cdot 4 \%$ were current smokers and $33.5 \%$ were former smokers. When compared with never smokers, current smokers were less likely to be current DS users (OR 0.76, 95\% CI 0.72, 0.80; data not shown) or to have used DS during the past 12 months (Table 3). The proportion of current DS users was $19.0 \%$ in smokers, $27 \cdot 2 \%$ in former smokers and $25 \cdot 2 \%$ in never smokers. Hierarchy of nutrients consumed ( $\mathrm{Mg}$, vitamin $\mathrm{B}_{6}$ and vitamin $\mathrm{C}$ ) was the same regardless of the smoking status (data not shown). $\beta$-Carotene supplement use was low overall ( $1.5 \%$ in smokers, $2.0 \%$ in former smoker and $1.7 \%$ in never smokers, $P=0.25$ ).

Motivations for DS use differed between current and never smokers (data not shown). Current smokers were less likely to indicate reasons such as 'overcome health problems' or 'meet specific needs related to a sports practice' (33.1 and 3.9\%, respectively), and were more likely to give reasons such as 'to counter stress' (17.5\%), 'to lose weight' (7.3\%), 'to improve intellectual performance' $(6 \cdot 1 \%)$ and 'to compensate for an inadequate diet' (6.5\%). In total, $7 \cdot 3 \%$ of current smokers used DS because of specific needs related to pregnancy (almost as much as in never smokers: 7.7\%). When compared with never smokers, current smokers were more likely to selfmedicate with DS, whereas having a medical prescription or receiving advice by a dietitian was reported by 30.9 and $2 \cdot 4 \%$, respectively $(v .36 \cdot 3$ and $3.2 \%$, respectively, among never smokers). Also, current smokers were more likely to purchase DS following non-medical advice (i.e. from 
Table 1. Dietary supplement (DS) use in men $(n 19398)$ and women $(n 60388)$ in the NutriNet-Santé cohort study, 2012

(Number of subjects and percentages)

\begin{tabular}{|c|c|c|c|c|c|c|}
\hline & \multicolumn{2}{|c|}{ All } & \multicolumn{2}{|c|}{ Men } & \multicolumn{2}{|c|}{ Women } \\
\hline & $n$ & $\%$ & $n$ & $\%$ & $n$ & $\%$ \\
\hline DS use during the past 12 months* (yes) & 32582 & $40 \cdot 8$ & 4729 & $24 \cdot 4$ & 27853 & $46 \cdot 1$ \\
\hline Current DS use $\geq 3 \mathrm{~d} /$ week (yes) & 19785 & $24 \cdot 8$ & 2828 & $14 \cdot 6$ & 16957 & $28 \cdot 1$ \\
\hline \multicolumn{7}{|l|}{ Types of DS used (current users only)† } \\
\hline $\mathrm{Mg}$ & 8324 & $42 \cdot 1$ & 1166 & $41 \cdot 2$ & 7158 & $42 \cdot 2$ \\
\hline Vitamin $\mathrm{B}_{6}$ & 5904 & 29.8 & 824 & $29 \cdot 1$ & 5080 & $30 \cdot 0$ \\
\hline Vitamin C & 5387 & $27 \cdot 2$ & 966 & $34 \cdot 2$ & 4421 & $26 \cdot 1$ \\
\hline $\mathrm{Zn}$ & 4974 & $25 \cdot 1$ & 767 & $27 \cdot 1$ & 4207 & $24 \cdot 8$ \\
\hline $\mathrm{Fe}$ & 4800 & $24 \cdot 3$ & 586 & $20 \cdot 7$ & 4214 & 24.9 \\
\hline Vitamin E & 4655 & 23.5 & 752 & $26 \cdot 6$ & 3903 & $23 \cdot 0$ \\
\hline Thiamin & 4456 & 22.5 & 396 & $14 \cdot 0$ & 1846 & $10 \cdot 9$ \\
\hline Vitamin D & 4421 & $22 \cdot 3$ & 710 & $25 \cdot 1$ & 3746 & $22 \cdot 1$ \\
\hline Riboflavin & 4381 & $22 \cdot 1$ & 481 & $17 \cdot 0$ & 3940 & $23 \cdot 2$ \\
\hline Folate & 4153 & $21 \cdot 0$ & 694 & 24.5 & 3687 & $21 \cdot 7$ \\
\hline Pantothenic acid & 3912 & $19 \cdot 8$ & 532 & $18 \cdot 8$ & 3621 & 21.4 \\
\hline $\mathrm{Ca}$ & 3885 & $19 \cdot 6$ & 550 & $19 \cdot 4$ & 3362 & $19 \cdot 8$ \\
\hline Niacin & 3397 & $17 \cdot 2$ & 605 & 21.4 & 3214 & $19 \cdot 0$ \\
\hline Se & 3358 & $17 \cdot 0$ & 531 & $18 \cdot 8$ & 2866 & $16 \cdot 9$ \\
\hline Vitamin $B_{12}$ & 3272 & $16 \cdot 5$ & 580 & $20 \cdot 5$ & 2778 & $16 \cdot 4$ \\
\hline Vitamin $B_{8}$ & 2882 & 14.6 & 529 & $18 \cdot 7$ & 2743 & $16 \cdot 2$ \\
\hline$n-3$ Fatty acids & 2733 & $13 \cdot 8$ & 377 & $13 \cdot 3$ & 2505 & $14 \cdot 8$ \\
\hline Vitamin A & 2242 & $11 \cdot 3$ & 292 & $10 \cdot 3$ & 2261 & 13.3 \\
\hline Evening primrose, borage or cod-liver oil & 1815 & $9 \cdot 2$ & 124 & 4.4 & 1691 & $10 \cdot 0$ \\
\hline Acerola, guarana or cranberry supplement & 1674 & 8.5 & 227 & 8.0 & 1147 & $6 \cdot 8$ \\
\hline 1 & 1443 & $7 \cdot 3$ & 210 & $7 \cdot 4$ & 1233 & $7 \cdot 3$ \\
\hline$\beta$-Carotene & 1389 & $7 \cdot 0$ & 203 & $7 \cdot 2$ & 1186 & $7 \cdot 0$ \\
\hline $\mathrm{P}$ & 1121 & $5 \cdot 7$ & 237 & 8.4 & 884 & $5 \cdot 2$ \\
\hline Ginseng & 1050 & $5 \cdot 3$ & 249 & 8.8 & 806 & 4.8 \\
\hline Fibres & 846 & $4 \cdot 3$ & 131 & 4.6 & 715 & $4 \cdot 2$ \\
\hline Amino acids/proteins & 681 & 3.4 & 186 & $6 \cdot 6$ & 495 & 2.9 \\
\hline Lutein & 670 & 3.4 & 125 & 4.4 & 545 & 3.2 \\
\hline Phyto-oestrogens & 376 & 1.9 & 38 & 1.3 & 338 & $2 \cdot 0$ \\
\hline $\mathrm{F}$ & 310 & 1.6 & 63 & $2 \cdot 2$ & 247 & 1.5 \\
\hline Vitamin $\mathrm{K}$ & 263 & 1.3 & 58 & $2 \cdot 1$ & 205 & 1.2 \\
\hline Zeaxanthin & 252 & 1.3 & 62 & $2 \cdot 2$ & 190 & $1 \cdot 1$ \\
\hline Retinol & 96 & 0.5 & 23 & 0.8 & 73 & 0.4 \\
\hline Other minerals $\ddagger$ & 3819 & $19 \cdot 3$ & 437 & $15 \cdot 5$ & 3448 & $20 \cdot 3$ \\
\hline Other herbal supplements & 2553 & $12 \cdot 9$ & 613 & $21 \cdot 7$ & 2120 & $12 \cdot 5$ \\
\hline
\end{tabular}

* $\geq 1$ DS during the 12 months preceding the DS questionnaire.

$\dagger$ Nutrients and other substances were taken alone or in combination.

$\ddagger \mathrm{K}, \mathrm{Cu}, \mathrm{Li}, \mathrm{Mn}, \mathrm{Ce}$ and others.

a friend/parent) than were non-smokers or former smokers (17.4, 14.4 and 13.8\%, respectively; data not shown).

\section{Dietary intake associated with dietary supplement use}

Among the 79786 subjects with available DS data, 55569 provided three dietary records and were normo-energy reporters, and thus were included in the following analyses.

Daily food intakes in DS users and non-users are compared in Table 4. Overall, DS users had a healthier diet than nonusers - they ate more vegetables, fruits, soups/broth, wholegrain foods, pulses, fish/seafood, breakfast cereals, sugar/ confectionery and meal substitutes, and drank more unsweetened drinks. They also ate less potatoes, dairy products, meat and offal, poultry, processed meat, cakes/biscuits/ pastries, snacks/pizzas and drank less alcoholic beverages.

Daily dietary energy and nutrient intake in DS users and non-users are compared in Table 5. DS users had higher food intakes of energy, total and simple carbohydrates, fibres, unsaturated fatty acids, but had lower intakes of alcohol, proteins, total lipids and SFA. They also had higher dietary intakes for most vitamins and minerals (i.e. thiamin, riboflavin, niacin, pantothenic acid, vitamin $\mathrm{B}_{6}$, folate, vitamin $\mathrm{B}_{12}, \beta$-carotene, vitamins $\mathrm{A}, \mathrm{C}, \mathrm{D}$ and $\mathrm{E}, \mathrm{Ca}, \mathrm{Fe}, \mathrm{Mg}$, $\mathrm{P}$ and $\mathrm{K}$ ). DS users had lower intakes of $\mathrm{Na}$ than did DS non-users.

The prevalences of dietary nutrient inadequacy (intakes from food) in DS users and non-users were compared by sex in Table 6. The prevalence of inadequacy was statistically significantly lower in DS users compared with non-users regarding most nutrients (thiamin, folate, vitamins $\mathrm{B}_{6}, \mathrm{~A}, \mathrm{C}$ and $\mathrm{E}, \mathrm{Ca}$ and $\mathrm{Mg}$ in men and women, plus riboflavin, pantothenic acid and $\mathrm{Fe}$ in women only). Only the prevalence of inadequacy for vitamin $\mathrm{B}_{12}$ intake was higher in women DS users than in non-users. 
Table 2. Reasons for use, circumstances of dietary supplement (DS) purchases and seasonality of use in DS users in the NutriNet-Santé cohort study ( $n$ 32 582; men $n$ 4729, women $n$ 27 853), 2012*

(Number of subjects and percentages)

\begin{tabular}{|c|c|c|c|c|c|c|}
\hline & \multicolumn{2}{|c|}{ All } & \multicolumn{2}{|c|}{ Men } & \multicolumn{2}{|c|}{ Women } \\
\hline & $n$ & $\%$ & $n$ & $\%$ & $n$ & $\%$ \\
\hline \multicolumn{7}{|l|}{ Reasons for DS use } \\
\hline Overcome tiredness & 13527 & 41.5 & 1733 & $36 \cdot 6$ & 11794 & $42 \cdot 3$ \\
\hline Stay healthy & 10997 & 33.8 & 2207 & $46 \cdot 7$ & 8790 & $31 \cdot 6$ \\
\hline Solve or overcome health problems & 10511 & $32 \cdot 3$ & 1224 & $25 \cdot 9$ & 9287 & $33 \cdot 3$ \\
\hline Beauty & 5001 & $15 \cdot 3$ & 224 & 4.7 & 4777 & $17 \cdot 2$ \\
\hline Counter stress & 4800 & $14 \cdot 7$ & 459 & $9 \cdot 7$ & 4341 & $15 \cdot 6$ \\
\hline Stay young & 2906 & 8.9 & 571 & $12 \cdot 1$ & 2335 & 8.4 \\
\hline Pregnancy & 2276 & $7 \cdot 0$ & 4 & $0 \cdot 1$ & 2272 & 8.2 \\
\hline Lose weight & 1620 & $5 \cdot 0$ & 151 & 3.2 & 1469 & $5 \cdot 3$ \\
\hline $\begin{array}{l}\text { Compensate for an inadequate dietary intake due to a } \\
\text { restrictive diet }\end{array}$ & 1524 & $4 \cdot 7$ & 233 & 4.9 & 1291 & $4 \cdot 6$ \\
\hline Improve intellectual performance & 1439 & 4.4 & 315 & $6 \cdot 7$ & 1124 & $4 \cdot 0$ \\
\hline Meet specific needs related to a sports practice & 1396 & $4 \cdot 3$ & 675 & $14 \cdot 3$ & 721 & $2 \cdot 6$ \\
\hline $\begin{array}{l}\text { Compensate for a dietary intake perceived as inadequate } \\
\text { (without a restrictive diet) }\end{array}$ & 1770 & $5 \cdot 4$ & 360 & $7 \cdot 6$ & 1410 & $5 \cdot 1$ \\
\hline Do not know & 83 & 0.3 & 19 & 0.4 & 64 & 0.2 \\
\hline \multicolumn{7}{|l|}{ Circumstances of DS purchases } \\
\hline With a medical prescription & 11044 & 33.9 & 905 & $19 \cdot 1$ & 10139 & $36 \cdot 4$ \\
\hline Following medical advice & 6828 & $21 \cdot 0$ & 738 & $15 \cdot 6$ & 6090 & $21 \cdot 9$ \\
\hline Following the advice of a pharmacist & 6763 & $20 \cdot 8$ & 666 & $14 \cdot 1$ & 6097 & $21 \cdot 9$ \\
\hline Following the advice of a dietitian & 885 & $2 \cdot 7$ & 104 & $2 \cdot 2$ & 781 & $2 \cdot 8$ \\
\hline Following the advice of another health professional & 2105 & $6 \cdot 5$ & 253 & $5 \cdot 3$ & 1845 & $6 \cdot 6$ \\
\hline Following the advice of a friend/family member & 5264 & $16 \cdot 2$ & 850 & $18 \cdot 0$ & 4414 & $15 \cdot 8$ \\
\hline Following non-professional advice received on site & 915 & $2 \cdot 8$ & 110 & $2 \cdot 3$ & 805 & $2 \cdot 9$ \\
\hline Discovered the DS in the store & 4188 & $12 \cdot 9$ & 687 & 14.5 & 3501 & $12 \cdot 6$ \\
\hline Read about the DS in a book & 3156 & $9 \cdot 7$ & 619 & $13 \cdot 1$ & 2537 & $9 \cdot 1$ \\
\hline Heard about the DS in the media & 2458 & $7 \cdot 5$ & 466 & $9 \cdot 9$ & 1992 & $7 \cdot 2$ \\
\hline Saw an advertisement & 1081 & 3.3 & 173 & 3.7 & 908 & $3 \cdot 3$ \\
\hline Other circumstances & 3056 & $9 \cdot 4$ & 635 & $13 \cdot 4$ & 2421 & $8 \cdot 7$ \\
\hline Do not know & 226 & 0.7 & 59 & $1 \cdot 2$ & 167 & 0.6 \\
\hline Higher DS use during a particular season (yes) & 17024 & $52 \cdot 2$ & 2638 & $55 \cdot 8$ & 14386 & $51 \cdot 6$ \\
\hline Winter & 9505 & $55 \cdot 8$ & 1405 & $53 \cdot 3$ & 8100 & $56 \cdot 3$ \\
\hline Autumn & 7033 & $41 \cdot 3$ & 788 & 29.9 & 6245 & 43.4 \\
\hline Spring & 4550 & $26 \cdot 7$ & 479 & $18 \cdot 2$ & 4071 & $28 \cdot 3$ \\
\hline Summer & 1252 & $7 \cdot 4$ & 120 & 4.5 & 1132 & 7.9 \\
\hline
\end{tabular}

${ }^{*}$ In subjects who reported use of $\geq 1$ DS during the 12 months preceding the DS questionnaire.

\section{Discussion}

The present study sheds light on DS use in a large sample of French adults. In the present analyses, $\mathrm{Mg}$ emerged as the most frequently used supplement, followed by vitamins $\mathrm{B}_{6}$ and $\mathrm{C}$, which is in accordance with the results from the Comportements et consommations alimentaires en France (CCAF) study ${ }^{(30)}$. The principal reason cited for DS use in the present study was 'to overcome tiredness', in line with the results of the ECCA (Enquête sur les Consommateurs de Compléments Alimentaires) study ${ }^{(13)}$. There was consistency between the most frequently cited DS used and the main reasons for use. Indeed, the European Food Safety Authority has recently recognised a causal relationship between some nutrient deficiency (notably $\mathrm{Mg}$, vitamin $\mathrm{C}$ and vitamin $\mathrm{B}_{6}$ ) and fatigue, thus authorising claims related to the management of fatigue as regards dietary products that contain at least $15 \%$ of the $\mathrm{RDA} / 100 \mathrm{~g}^{(31-33)}$. In contrast, a well-founded reason that could motivate DS use (i.e. 'to compensate for inadequate dietary intake') was cited by only $10 \cdot 1 \%$ of the users. In addition, specific conditions (often associated with physical or psychological discomfort) such as undergoing a restrictive diet, pregnancy, menopause and chronic emotional or physical pain were associated with a higher DS use in the present study. DS use did not appear to be a temporary trend, as it was often reported over a long period of time, suggesting that long-term effects on health are possible. Winter was also reported as the main season for DS use in the INCA2 (Étude Individuelle Nationale des Consommations Alimentaires 2) and the ECCA studies ${ }^{(8,14)}$.

About half of the DS users were self-medicated, whereas $21 \%$ of the DS purchases followed medical advice and another $33 \%$ were purchased with a prescription. In addition, the role of the pharmacist was noteworthy, as it represented more than $20 \%$ of the reported motivations for DS purchases. These results were in accordance with the INCA2 study ${ }^{(14)}$, where medical prescription or advice represented $52 \%$ and advice from a pharmacist represented 18\%. It has been suggested that pharmacists might be ill-equipped to counsel patients on these products and an ethical issue stemming from the profit motive may occur ${ }^{(34)}$. 
Table 3. Sociodemographic, lifestyle and behavioural correlates of dietary supplement (DS) use in the NutriNet-Santé cohort, 2012 ( $n 32582$ DS users $^{*}$ and 47204 non-users)

(Number of subjects and percentages; odds ratios and $95 \%$ confidence intervals)

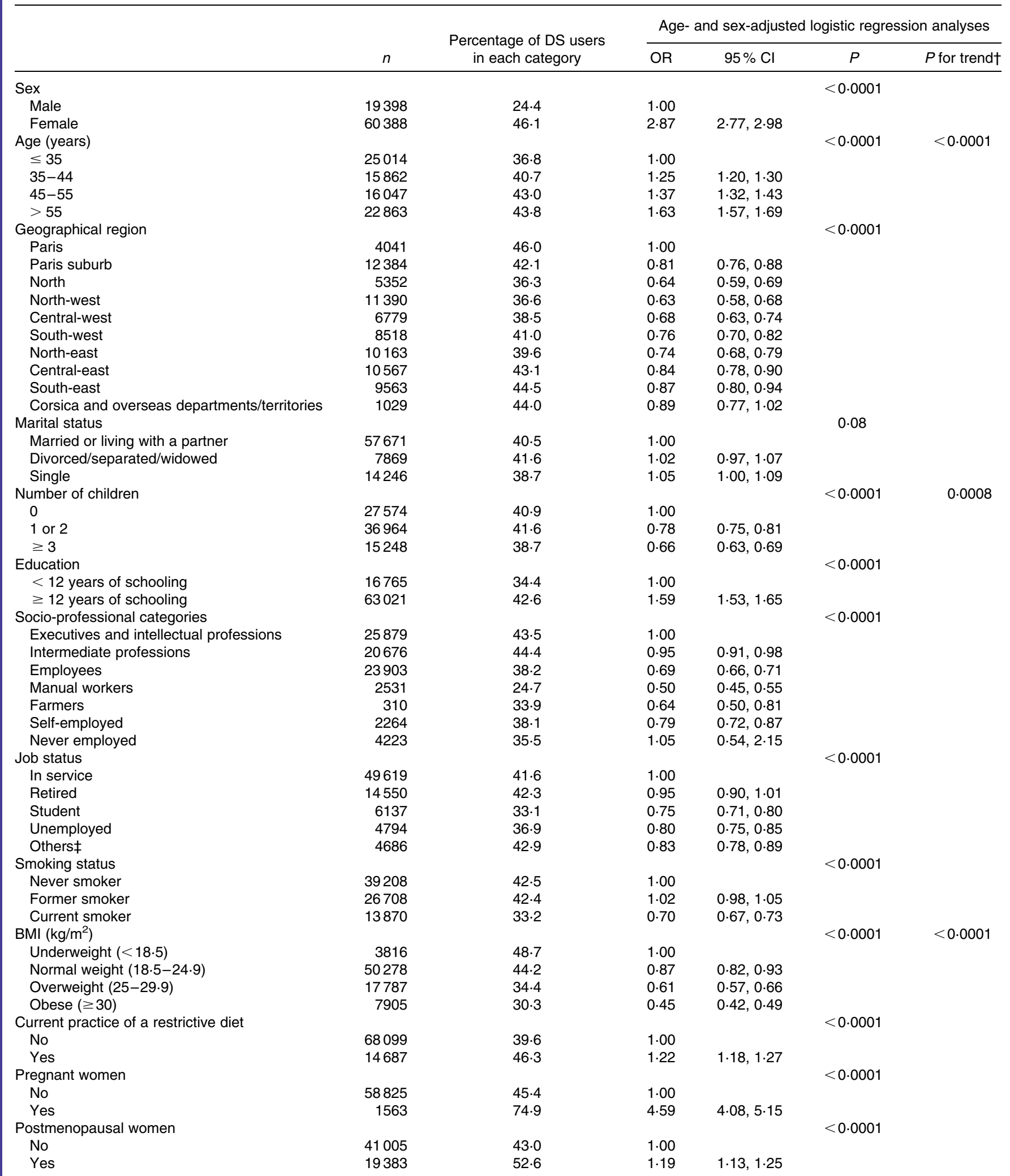


Table 3. Continued

\begin{tabular}{|c|c|c|c|c|c|c|}
\hline & \multirow[b]{2}{*}{$n$} & \multirow{2}{*}{$\begin{array}{l}\text { Percentage of DS users } \\
\text { in each category }\end{array}$} & \multicolumn{4}{|c|}{ Age- and sex-adjusted logistic regression analyses } \\
\hline & & & OR & $95 \% \mathrm{Cl}$ & $P$ & $P$ for trend $\dagger$ \\
\hline Leisure-time physical activity§ & & & & & $<0.0001$ & $<0.0001$ \\
\hline Low & 16212 & 39.5 & 1.00 & & & \\
\hline Moderate & 28350 & 44.5 & $1 \cdot 22$ & $1 \cdot 17,1 \cdot 27$ & & \\
\hline High & 23209 & $42 \cdot 5$ & $1 \cdot 16$ & $1 \cdot 11,1 \cdot 21$ & & \\
\hline $\begin{array}{l}\text { Self-perceived limitations in daily activities due } \\
\text { to a negative emotional state } \|\end{array}$ & & & & & $<0.0001$ & \\
\hline No & 45083 & $45 \cdot 0$ & 1.00 & & & \\
\hline Yes & 19778 & $51 \cdot 0$ & $1 \cdot 22$ & $1 \cdot 18,1 \cdot 26$ & & \\
\hline Chronic physical pain\| & & & & & $<0.0001$ & \\
\hline No & 18637 & $42 \cdot 3$ & 1.00 & & & \\
\hline Yes & 46224 & $48 \cdot 7$ & $1 \cdot 24$ & $1 \cdot 20,1 \cdot 29$ & & \\
\hline $\begin{array}{l}\text { Knowledge of official nutritional } \\
\text { recommendations }\end{array}$ & & & & & $<0.0001$ & $<0.0001$ \\
\hline Poor $(0-2)$ & 22896 & $41 \cdot 1$ & 1.00 & & & \\
\hline Average (3) & 21750 & $43 \cdot 8$ & 1.03 & $0.99,1.07$ & & \\
\hline Good (4-5) & 26651 & $48 \cdot 2$ & $1 \cdot 16$ & $1 \cdot 12,1 \cdot 21$ & & \\
\hline Organic food consumption ${ }^{\star \star}$ & & & & & $<0.0001$ & \\
\hline Never (avoid organic products) & 17222 & $37 \cdot 0$ & 1.00 & & & \\
\hline Indifferent to organic food & 4860 & $32 \cdot 0$ & 0.94 & $0.87,1.00$ & & \\
\hline Occasional consumption & 25377 & 43.7 & 1.39 & $1.34,1.45$ & & \\
\hline Regular consumption & 11365 & $60 \cdot 8$ & $2 \cdot 61$ & $2 \cdot 48,2 \cdot 74$ & & \\
\hline
\end{tabular}

*DS users were defined as subjects who used $\geq 1$ DS during the 12 months preceding the DS questionnaire.

†Tests for linear trend were performed using the ordinal score on categories of each variable. DS users were compared with non-users for all the characteristics. The probability of being a DS user is modelled.

$\ddagger$ Sabbatical leave, preparation for an examination, homemaker, illness.

$\S$ Because of missing values, sample sizes were 28876 supplement users and 38895 non-users.

|| Because of missing values, sample sizes were 30374 supplement users and 34487 non-users.

I From the French National Nutrition and Health Program. Because of missing values, sample sizes were 31780 supplement users and 39517 non-users.

** Determined by multiple correspondence analysis using data from the organic food consumption measure (five clusters defined by the first three discriminant axes). Because of missing values, sample sizes were 25947 supplement users and 32877 non-users.

Table 4. Comparison of daily food intake (g/d) in dietary supplement (DS) users* ${ }^{*}(24191)$ and non-users ( $n$ 31 378) in the NutriNet-Santé cohort study†

(Mean values with their standard errors)

\begin{tabular}{|c|c|c|c|c|c|}
\hline & \multicolumn{2}{|c|}{ Non-users $\ddagger$} & \multicolumn{2}{|c|}{ Usersł } & \multirow[b]{2}{*}{$P$ for trend } \\
\hline & Mean & SE & Mean & SE & \\
\hline Vegetables & $202 \cdot 0$ & 0.7 & $220 \cdot 7$ & 0.9 & $<0.0001$ \\
\hline Fruits & $230 \cdot 1$ & 1.0 & $257 \cdot 1$ & 1.3 & $<0.0001$ \\
\hline Soups and broths & $26 \cdot 8$ & 0.3 & 28.8 & 0.4 & $<0.0001$ \\
\hline Potatoes and tubers & $47 \cdot 6$ & 0.3 & $44 \cdot 1$ & 0.4 & $<0.0001$ \\
\hline Pasta, rice, semolina, bread, flour, other cereals & $178 \cdot 8$ & 0.5 & 178.9 & 0.6 & 0.8 \\
\hline Whole-grain foods & $51 \cdot 0$ & 0.4 & $64 \cdot 1$ & 0.5 & $<0.0001$ \\
\hline Pulses & 8.4 & 0.1 & 9.5 & 0.2 & $<0.0001$ \\
\hline Dairy products & $203 \cdot 2$ & 0.9 & $197 \cdot 7$ & $1 \cdot 2$ & $<0.0001$ \\
\hline Meat and offal & $49 \cdot 6$ & 0.3 & $44 \cdot 2$ & 0.3 & $<0.0001$ \\
\hline Poultry & $26 \cdot 3$ & 0.2 & 24.9 & 0.2 & $<0.0001$ \\
\hline Eggs & $12 \cdot 2$ & 0.1 & $12 \cdot 5$ & 0.2 & 0.09 \\
\hline Fish and seafood & 37.4 & 0.3 & $40 \cdot 1$ & 0.3 & $<0.0001$ \\
\hline Processed meat & $35 \cdot 3$ & 0.2 & $32 \cdot 0$ & 0.3 & $<0.0001$ \\
\hline Fats and sauces & 37.9 & 0.1 & 38.2 & 0.2 & 0.04 \\
\hline Fats (oil, butter, margarine) & 21.4 & 0.1 & $22 \cdot 1$ & 0.1 & 0.1 \\
\hline Breakfast cereals & 7.4 & 0.1 & $10 \cdot 0$ & 0.1 & $<0.0001$ \\
\hline Sugar/confectionery/dried fruits/desserts & $62 \cdot 7$ & 0.4 & $66 \cdot 9$ & 0.5 & $<0.0001$ \\
\hline Cakes/biscuits/pastries & $53 \cdot 6$ & 0.3 & $52 \cdot 4$ & 0.4 & 0.009 \\
\hline Snacks, pizza, pies & $36 \cdot 2$ & 0.3 & 33.5 & 0.4 & $<0.0001$ \\
\hline Unsweetened soft drinks & $1040 \cdot 2$ & 3.4 & $1170 \cdot 6$ & $4 \cdot 2$ & $<0.0001$ \\
\hline Sweetened soft drinks & $58 \cdot 2$ & 0.7 & $52 \cdot 3$ & 0.8 & $<0.0001$ \\
\hline Alcoholic drinks & $124 \cdot 1$ & 0.9 & 114.8 & $1 \cdot 1$ & $<0.0001$ \\
\hline Meal substitutes & 0.8 & 0.1 & 1.9 & 0.1 & $<0.0001$ \\
\hline
\end{tabular}

* DS users were defined as subjects who used $\geq 1$ DS during the 12 months preceding the DS questionnaire. $\dagger$ In subjects with three dietary records at baseline.

‡Logistic regression analysis comparing DS users and non-users with adjustment for sex, age and energy intake. 
Table 5. Comparison of daily dietary energy and nutrient intake in dietary supplement (DS) users* ${ }^{*}$ 2 24191$)$ and non-users (n 31378) in the NutriNet-Santé cohort study $\dagger$

(Mean values with their standard errors)

\begin{tabular}{|c|c|c|c|c|c|}
\hline & \multicolumn{2}{|c|}{ Non-users $\ddagger$} & \multicolumn{2}{|c|}{ Usersł } & \multirow[b]{2}{*}{$P$ for tren } \\
\hline & Mean & SE & Mean & SE & \\
\hline Energy & & & & & $<0.0001$ \\
\hline $\mathrm{kcal}$ & $2035 \cdot 0$ & $2 \cdot 7$ & 2071.6 & 3.4 & \\
\hline $\mathrm{kJ}$ & 8514.4 & $11 \cdot 3$ & 8667.6 & $14 \cdot 2$ & \\
\hline Alcohol (g) & $10 \cdot 6$ & $0 \cdot 1$ & 9.8 & 0.1 & $<0.0001$ \\
\hline Total carbohydrates $(\mathrm{g})$ & $200 \cdot 4$ & 0.2 & 203.4 & 0.3 & $<0.0001$ \\
\hline Simple carbohydrates $(\mathrm{g})$ & $91 \cdot 3$ & 0.2 & 94.7 & 0.2 & $<0.0001$ \\
\hline Starch $(g)$ & 108.4 & 0.2 & $108 \cdot 0$ & 0.2 & 0.1 \\
\hline Fibres (g) & 18.6 & 0.0 & $20 \cdot 4$ & 0.0 & $<0.0001$ \\
\hline Proteins $(\mathrm{g})$ & $81 \cdot 0$ & 0.1 & $80 \cdot 2$ & 0.1 & $<0.0001$ \\
\hline Total lipids (g) & $78 \cdot 8$ & 0.1 & 78.4 & 0.1 & 0.0003 \\
\hline SFA (g) & 32.5 & 0.0 & 31.5 & 0.1 & $<0.0001$ \\
\hline MUFA (g) & 28.5 & 0.0 & 28.8 & 0.0 & $<0.0001$ \\
\hline PUFA (g) & 11.9 & 0.0 & $12 \cdot 3$ & 0.0 & $<0.0001$ \\
\hline Thiamin (mg) & $1 \cdot 2$ & 0.0 & 1.3 & 0.0 & $<0.0001$ \\
\hline Riboflavin (mg) & 1.7 & 0.0 & 1.8 & 0.0 & $<0.0001$ \\
\hline Niacin (mg) & $18 \cdot 2$ & 0.0 & $18 \cdot 7$ & 0.0 & $<0.0001$ \\
\hline Pantothenic acid (mg) & 5.4 & 0.0 & 5.5 & 0.0 & $<0.0001$ \\
\hline Vitamin $B_{6}(\mathrm{mg})$ & 1.7 & 0.0 & 1.8 & 0.0 & $<0.0001$ \\
\hline Folate $(\mu \mathrm{g})$ & $331 \cdot 2$ & 0.6 & $354 \cdot 3$ & 0.8 & $<0.0001$ \\
\hline Vitamin $B_{12}(\mu \mathrm{g})$ & 5.5 & 0.0 & $5 \cdot 8$ & 0.1 & $<0.0001$ \\
\hline Retinol $(\mu \mathrm{g})$ & $518 \cdot 8$ & $5 \cdot 3$ & 512.5 & $6 \cdot 6$ & 0.4 \\
\hline$\beta$-Carotene $(\mu \mathrm{g})$ & 3677.9 & $17 \cdot 4$ & 4063.8 & $21 \cdot 8$ & $<0.0001$ \\
\hline Total vitamin $\mathrm{A}(\mu \mathrm{g})$ & $1197 \cdot 2$ & $12 \cdot 5$ & $1251 \cdot 8$ & $15 \cdot 7$ & 0.003 \\
\hline Vitamin C (mg) & $113 \cdot 2$ & 0.5 & $121 \cdot 8$ & 0.6 & $<0.0001$ \\
\hline Vitamin D $(\mu \mathrm{g})$ & $2 \cdot 7$ & 0.0 & 2.9 & 0.0 & $<0.0001$ \\
\hline Vitamin E $(\mu \mathrm{g})$ & $10 \cdot 1$ & 0.0 & $10 \cdot 8$ & 0.0 & $<0.0001$ \\
\hline $\mathrm{Na}(\mathrm{mg})$ & 2517.9 & 3.7 & 2484.7 & 4.7 & $<0.0001$ \\
\hline $\mathrm{Ca}(\mathrm{mg})$ & 889.9 & 1.6 & $910 \cdot 2$ & $2 \cdot 0$ & $<0.0001$ \\
\hline $\mathrm{Fe}(\mathrm{mg})$ & $12 \cdot 4$ & 0.0 & $13 \cdot 1$ & 0.0 & $<0.0001$ \\
\hline $\mathrm{Mg}(\mathrm{mg})$ & 311.3 & 0.5 & $330 \cdot 7$ & 0.6 & $<0.0001$ \\
\hline $\mathrm{P}(\mathrm{mg})$ & $1256 \cdot 0$ & 1.5 & $1281 \cdot 1$ & 1.9 & $<0.0001$ \\
\hline $\mathrm{K}(\mathrm{mg})$ & 2984.9 & 3.9 & 3103.4 & 4.9 & $<0.0001$ \\
\hline $\mathrm{Zn}(\mathrm{mg})$ & $10 \cdot 4$ & 0.0 & $10 \cdot 3$ & 0.0 & 0.05 \\
\hline
\end{tabular}

Concerning the sociodemographic, lifestyle and behavioural profile of DS users, several studies in other developed countries have also found that supplement users were more often women $^{(8,12)}{\text {, } \text { older }^{(35)} \text {, had a higher level of education }}^{(7)}$, belonged to a higher socio-professional category ${ }^{(36)}$ and lived in small-sized households ${ }^{(8)}$. Lower BMI ${ }^{(8)}$, higher leisure-time physical activity levels ${ }^{(3,10)}$ and healthier lifestyle among users than non-users ${ }^{(37-39)}$ have also been reported. In addition, we observed, for the first time in France, that DS users were more likely to report increased knowledge of nutritional recommendations and increased organic food consumption, adding consistency to the 'healthy DS users' profile.

As reported previously, using another French cohort, we observed that current smokers were less likely to be DS users than were non-smokers ${ }^{(10)}$, which is consistent with a healthier lifestyle. However, DS use in smokers was nonnegligible (19\%), despite the fact that the potential health effects of DS use in association with tobacco smoking are not well known. Notably, it has been shown that $\beta$-carotene supplements increase cancer risk in smokers ${ }^{(16,40)}$. $\beta$-Carotene DS use was low in the present study, but interestingly, it was not lower among smokers, despite the demonstrated cancer risk in that subgroup. This finding suggests that smokers might not be aware of that risk, or that health care professionals might not be well informed ${ }^{(41)}$. The most commonly used DS were the same regardless of smoking status, but the reasons for use differed. When compared with never smokers, smokers were more likely to use DS to overcome stress, to lose weight, to compensate for inadequate dietary intake and were more likely to self-medicate, which increases the potential risks associated with DS use in this sub-population.

Considering food and dietary nutrient intake, DS users had a healthier diet than non-users, as observed previously ${ }^{(2,12,38,42)}$ The prevalence of inadequate dietary nutrient intake was also lower in DS users compared with non-users for most micronutrients, in both men and women, as reported 
Table 6. Comparison of the prevalence of dietary nutrient inadequacy stratified by sex and dietary supplement (DS) use in the NutriNet-Santé cohort study* (Odds ratios and $95 \%$ confidence intervals)

\begin{tabular}{|c|c|c|c|c|c|c|c|c|c|c|}
\hline & \multicolumn{5}{|c|}{ Men } & \multicolumn{5}{|c|}{ Women } \\
\hline & \multicolumn{2}{|c|}{ Prevalence of inadequacy† (\%) } & \multirow[b]{2}{*}{$\begin{array}{c}\text { OR for } \\
\text { inadequacy§ }\end{array}$} & \multirow[b]{2}{*}{$95 \% \mathrm{Cl}$} & \multirow[b]{2}{*}{$P$} & \multicolumn{2}{|c|}{ Prevalence of inadequacy† (\%) } & \multirow[b]{2}{*}{$\begin{array}{c}\text { OR for } \\
\text { inadequacy§ }\end{array}$} & \multirow[b]{2}{*}{$95 \% \mathrm{Cl}$} & \multirow[b]{2}{*}{$P$} \\
\hline & $\begin{array}{l}\text { DS non-users } \\
(n \text { 9889) }\end{array}$ & $\begin{array}{l}\text { DS users } \\
(n 3450) \ddagger\end{array}$ & & & & $\begin{array}{c}\text { DS non-users } \\
(n 21489) \ddagger\end{array}$ & $\begin{array}{l}\text { DS users } \\
(n 20741)\end{array}$ & & & \\
\hline Thiamin & $16 \cdot 3$ & $13 \cdot 6$ & 0.81 & $0.73,0.90$ & $<0.0001$ & $10 \cdot 9$ & $8 \cdot 8$ & 0.84 & $0.79,0.88$ & $<0.0001$ \\
\hline Riboflavin & 3.8 & 3.5 & 0.95 & $0.80,1 \cdot 12$ & 0.5 & $14 \cdot 7$ & $11 \cdot 2$ & 0.90 & $0.85,0.95$ & 0.0002 \\
\hline Niacin & 0.1 & 0.6 & 0.89 & $0.69,1.14$ & 0.3 & 0.9 & 0.7 & 0.99 & $0.88,1.11$ & 0.8 \\
\hline Pantothenic acid & 3.3 & $2 \cdot 1$ & 0.86 & $0.71,1.04$ & 0.1 & $16 \cdot 4$ & 11.4 & 0.87 & $0.83,0.92$ & $<0.0001$ \\
\hline Vitamin $\mathrm{B}_{6}$ & $16 \cdot 4$ & 11.6 & 0.64 & $0.57,0.72$ & $<0.0001$ & 15.5 & $10 \cdot 4$ & 0.79 & $0.75,0.83$ & $<0.0001$ \\
\hline Folate & 7.4 & 4.4 & 0.71 & $0.61,0.83$ & $<0.0001$ & $10 \cdot 1$ & 4.6 & 0.62 & $0.58,0.66$ & $<0.0001$ \\
\hline Vitamin $B_{12}$ & 0.1 & 0.6 & 1.23 & $1.00,1.51$ & 0.06 & 2.4 & 2.9 & 1.14 & $1.07,1.22$ & 0.0002 \\
\hline Vitamin A & 5.0 & $4 \cdot 1$ & 0.84 & $0.74,0.95$ & 0.007 & 1.4 & 0.6 & 0.73 & $0.68,0.80$ & $<0.0001$ \\
\hline Vitamin C & $30 \cdot 6$ & $21 \cdot 0$ & 0.72 & $0.66,0.79$ & $<0.0001$ & 34.8 & 30.6 & 0.76 & $0.73,0.79$ & $<0.0001$ \\
\hline Vitamin E & $33 \cdot 3$ & 23.4 & 0.70 & $0.63,0.76$ & $<0.0001$ & $49 \cdot 6$ & 38.3 & 0.72 & $0.69,0.76$ & $<0.0001$ \\
\hline $\mathrm{Ca}$ & 18.4 & $17 \cdot 3$ & 0.85 & $0.76,0.94$ & 0.002 & $34 \cdot 3$ & 33.0 & 0.87 & $0.83,0.91$ & $<0.0001$ \\
\hline $\mathrm{Fe}$ & 0.0 & 0.0 & 0.75 & $0.51,1.12$ & 0.2 & 54.8 & $40 \cdot 7$ & 0.76 & $0.73,0.80$ & $<0.0001$ \\
\hline $\mathrm{Mg}$ & $51 \cdot 3$ & $38 \cdot 8$ & 0.60 & $0.55,0.66$ & $<0.0001$ & 60.4 & 46.5 & 0.67 & $0.64,0.70$ & $<0.0001$ \\
\hline P & 0.2 & 0.1 & $0 \cdot 18$ & $0.04,0.90$ & 0.04 & 0.0 & 0.0 & 0.88 & $0.69,1.13$ & 0.3 \\
\hline $\mathrm{Zn}$ & $13 \cdot 2$ & $12 \cdot 8$ & 1.03 & $0.93,1.15$ & 0.6 & 22.9 & 21.5 & 1.02 & $0.97,1.07$ & 0.5 \\
\hline
\end{tabular}

${ }^{*}$ In subjects with three dietary records at baseline.

†The probability of dietary nutrient intakes below the estimated average requirements for the French population.

$\ddagger D S$ users were defined as subjects who used $\geq 1$ DS during the 12 months preceding the DS questionnaire.

§Logistic regression analysis comparing DS users and non-users, adjusted for age and energy intake. Reference, DS non-users. 
previously ${ }^{(8,37,43)}$, except for vitamin $\mathrm{B}_{12}$ in women. In fact, DS users ate less meat than did non-users, meat being a major contributor of vitamin $\mathrm{B}_{12}$ intake.

The present study highlighted a risk of insufficient dietary intakes as regards several nutrients in the whole population study. Increased nutrient intake through tablets or pills under medical supervision is justified under certain physiological situations (such as pregnancy). However, several arguments encourage caution regarding supplement use for the general population. They pertain to the quality and safety of $\mathrm{DS}^{(44)}$, the absence of clear benefits in chronic disease management in well-nourished populations, the need-use disparity (i.e. increased DS use by those who have the least need for them, as shown in the present study), the behavioural impact (e.g. people might believe that DS use can act as a substitute for a diversified and balanced diet) and the potential deleterious effects of some DS in certain population subgroups (e.g. $\beta$-carotene use in smokers ${ }^{(15-17)}$, or DS-drug interactions in individuals taking certain medications $\left.{ }^{(45,46)}\right)$. Thus, the official recommendation for the general population is to increase dietary variety ${ }^{(47)}$ and improve healthy food choices rather than to use DS in order to achieve adequate nutrient intakes.

Several limitations of the present study should be mentioned. Caution is needed in extrapolating the present results to the general population, as the present study was based on a volunteer sample. Participants were primarily women, mostly belonging to the highest socio-professional categories than the general population. For instance, the proportion of DS users in the present study was slightly higher than the prevalence of DS use assessed in the French INCA2 study (2006) using a nationally representative sample. Similarly, the percentage of organic food consumers in the present study was higher than that in the general population (about $60 \%$ in the NutriNet-Santé study compared with $43 \%$ in a representative French study $\left.{ }^{(48)}\right)$. This could partly be attributed to sample composition (i.e. the large proportion of women in the present study, who tend to consume more $\operatorname{DS}^{(11,13,14)}$ and organic foods ${ }^{(48)}$, than men) and to the self-selection of participants in a nutrition-focused study. However, the present Web-based study allowed the inclusion of subjects from lower socio-professional categories, who are usually difficult to reach. Next, significant associations occurring purely by chance cannot be excluded. However, the present results are hypothesis-driven and supported by available data in the literature. The number of statistically significant results observed in the present study was far above the 5\% error of the first kind and most of them were highly significant $(P<0.0001)$. Finally, data collection is based on self-administered questionnaires and the DS questionnaire might engender a memory bias because subjects were asked for the motivations and circumstances of their DS purchases over the past 12 months.

In conclusion, the NutriNet-Santé study provided new and detailed information on DS use. Overall, the present results suggest that DS users had an overall healthier profile (in terms of diet, smoking status, physical activity and other parameters) and better knowledge of nutritional recommendations. This is consistent with the findings observed in other developed countries $^{(3,37-39,49,50)}$, which suggests that despite very different behaviours, opinions and culture regarding food, health and nutrition, the profile of DS users is overall stable across such countries. The present study also highlighted the importance of self-medication practices regarding DS use (more than $45 \%)$. The large sample of subjects allowed analysing subgroups of interest (such as smokers), for whom some DS may increase the risk regarding chronic pathologies such as cancer. Current smokers used less DS than did non-smokers, but their DS consumption was substantial (19.0\%) and they were more likely to self-medicate. Finally, the correlates of DS use highlighted in the present study could be useful in properly controlling for potential confounders in future prospective aetiological studies on the relationship between DS use and chronic disease.

\section{Acknowledgements}

The NutriNet-Sante cohort study is funded by the following public institutions: Ministère de la Santé (DGS); Institut de Veille Sanitaire (InVS); Institut National de la Prévention et de l'Education pour la Santé (INPES); Fondation pour la Recherche Médicale (FRM); Institut National de la santé et de la Recherche Médicale (INSERM); Institut National de la Recherche agronomique (INRA); Conservatoire National des Arts et Métiers (CNAM); Paris 13 University. The authors' responsibilities were as follows: $\mathrm{C}$. P. and $\mathrm{M}$. T. designed the research; C. P., M. T. and S. H. conducted the research; C. P. analysed the data and led the writing; M. T. supervised the study; V. A. A., S. P., E. K.-G., C. L., S. H. and M. T. contributed to the data interpretation and revised each draft for important intellectual content; M. T. had primary responsibility for the final content. All authors read and approved the final manuscript. The authors declare that there are no conflicts of interest.

\section{References}

1. Bailey RL, Gahche JJ, Lentino CV, et al. (2011) Dietary supplement use in the United States, 2003-2006. J Nutr 141, 261-266

2. Gahche J, Bailey R, Burt V, et al. (2011) Dietary supplement use among U.S. adults has increased since NHANES III (1988-1994). NCHS Data Brief 1-8.

3. Gardiner P, Kemper KJ, Legedza A, et al. (2007) Factors associated with herb and dietary supplement use by young adults in the United States. BMC Complement Altern Med 7, 39 .

4. Murphy SP, Wilkens LR, Monroe KR, et al. (2011) Dietary supplement use within a multiethnic population as measured by a unique inventory method. J Am Diet Assoc 111, 1065-1072.

5. Skeie G, Braaten T, Hjartaker A, et al. (2009) Use of dietary supplements in the European Prospective Investigation into Cancer and Nutrition calibration study. Eur J Clin Nutr 63, S226-S238.

6. Marques-Vidal P, Pecoud A, Hayoz D, et al. (2007) Prevalence and characteristics of vitamin or dietary supplement 
users in Lausanne, Switzerland: the CoLaus study. Eur J Clin Nutr 63, 273-281.

7. Mileva-Peceva $\mathrm{R}$, Zafirova-Ivanovska $\mathrm{B}$, Milev $\mathrm{M}$, et al. (2011) Sociodemographic predictors and reasons for vitamin and/or mineral food supplement use in a group of outpatients in Skopje. Prilozi 32, 127-139.

8. Touvier M, Boutron-Ruault MC, Volatier JL, et al. (2005) Efficacy and safety of regular vitamin and mineral supplement use in France: results from the ECCA study. Int J Vitam Nutr Res 75, 201-209.

9. Picciano MF \& McGuire MK (2009) Use of dietary supplements by pregnant and lactating women in North America. Am J Clin Nutr 89, 663-667.

10. Touvier M, Kesse E, Volatier JL, et al. (2006) Dietary and cancer-related behaviors of vitamin/mineral dietary supplement users in a large cohort of French women. Eur $J$ Nutr 45, 205-214.

11. Centre de Recherche pour l'Etude et l'Observation des Conditions de vie (CREDOC) (2004) Comportements et consommations alimentaires en France (CCAF 2004) (Behavior and Food Consumption in France (CCAF 2004)). Paris: Editions TEC \& DOC.

12. Pilorin T \& Hebel P (2012) Consommation de compléments alimentaires en France: profil des consommateurs et contribution à l'équilibre nutritionnel (Consumption of dietary supplements in France: consumer patterns and contribution to the nutritional balance). Cahi Nutr Diét 47, 147-155.

13. Touvier M, Dufour A, Gourillon S, et al. (2003) Les forts consommateurs de compléments alimentaires en France: résultats de l'enquête ECCA (Regular dietary supplement users in France: results from the ECCA survery). Cabi Nutr Diét 38, 187-194.

14. Agence Francaise de sécurité sanitaire des aliments (AFSSA) (2009) Étude Individuelle Nationale des Consommations Alimentaires 2 (INCA 2) (2006-2007) (Second National Individual study of Dietary Consumption (2006-2007)). Paris: AFSSA.

15. Albanes D, Heinonen OP, Taylor PR, et al. (1996) Alphatocopherol and beta-carotene supplements and lung cancer incidence in the alpha-tocopherol, beta-carotene cancer prevention study: effects of base-line characteristics and study compliance. J Natl Cancer Inst 88, 1560-1570.

16. Druesne-Pecollo N, Latino-Martel P, Norat T, et al. (2010) Beta-carotene supplementation and cancer risk: a systematic review and metaanalysis of randomized controlled trials. Int J Cancer 127, 172-184.

17. Touvier M, Kesse E, Clavel-Chapelon F, et al. (2005) Dual association of beta-carotene with risk of tobacco-related cancers in a cohort of French women. J Natl Cancer Inst 97, 1338-1344.

18. Hercberg S, Castetbon K, Czernichow S, et al. (2010) The Nutrinet-Santé Study: a web-based prospective study on the relationship between nutrition and health and determinants of dietary patterns and nutritional status. BMC Public Health 10, 242.

19. Craig CL, Marshall AL, Sjöström M, et al. (2003) International physical activity questionnaire: 12-country reliability and validity. Med Sci Sports Exerc 35, 1381-1395.

20. Vergnaud AC, Touvier M, Mejean C, et al. (2011) Agreement between web-based and paper versions of a sociodemographic questionnaire in the NutriNet-Santé study. Int J Public Health 56, 407-417.

21. Touvier M, Kesse-Guyot E, Mejean C, et al. (2011) Comparison between an interactive web-based self-administered $24 \mathrm{~h}$ dietary record and an interview by a dietitian for large-scale epidemiological studies. Br J Nutr 105, 1055-1064.
22. Touvier M, Mejean C, Kesse-Guyot E, et al. (2010) Comparison between web-based and paper versions of a self-administered anthropometric questionnaire. Eur $J$ Epidemiol 25, 287-296.

23. Hercberg S, Deheeger M \& Preziosi P (2002) SU.VI.MAX Portions alimentaires manuel-photos pour l'estimation des quantités (SU.VI.MAX. Photograph Book for the Estimation of portion sizes). Paris: Editions Polytechnica.

24. Plan National Nutrition Santé (PNNS) (2009) Nutrition et Prévention des cancers: des connaissances scientifiques aux recommandations (Nutrition and Cancer Prevention: From Scientific Knowledge to Recommendations). Paris: Comelli.

25. Black AE (2000) Critical evaluation of energy intake using the Goldberg cut-off for energy intake:basal metabolic rate. A practical guide to its calculation, use and limitations. Int J Obes Relat Metab Disord 24, 1119-1130.

26. Martin A (2001) Apports nutritionnels conseillés pour la population française (Recommended Dietary Allowances for the French Population), 3rd ed. Paris: Tec \& Doc Lavoisier.

27. Carriquiry AL (1999) Assessing the prevalence of nutrient inadequacy. Public Health Nutr 2, 23-33.

28. National Research Council (1985) Nutrient Adequacy: Assessment using Food Consumption Surveys, Subcommittee on Criteria for Dietary Evaluation. Washington, DC: National Research Council.

29. Nusser SM, Carriquiry AL, Dodd KW, et al. (1996) A semiparametric transformation approach to estimating usual daily intake distributions. J Am Stat Assoc 91, 1440-1449.

30. Gainier C, Hebel P (2005) Qui sont les consommateurs de compléments alimentaires et les consommateurs d'aliments santé? (Who are the consumers of dietary supplements and health food consumers?) In IREMAS 2eme colloque international, Paris.

31. EFSA Panel on Dietetic Products NaAN (2010) Scientific opinion on the substantiation of health claims related to magnesium and "hormonal health" (ID 243), reduction of tiredness and fatigue (ID 244), contribution to normal psychological functions (ID 245, 246), maintenance of normal blood glucose concentrations (ID 342), maintenance of normal blood pressure (ID 344, 379), protection of DNA, proteins and lipids from oxidative damage (ID 351), maintenance of the normal function of the immune system (ID 352), maintenance of normal blood pressure during pregnancy (ID 367), resistance to mental stress (ID 375, 381), reduction of gastric acid levels (ID 376), maintenance of normal fat metabolism (ID 378) and maintenance of normal muscle contraction (ID 380, ID 3083) pursuant to Article 13(1) of Regulation (EC) No. 1924/2006. EFSA J $\mathbf{8}, 1-35$.

32. EFSA Panel on Dietetic Products NaAN (2010) Scientific opinion on the substantiation of health claims related to vitamin $\mathrm{B}_{6}$ and contribution to normal homocysteine metabolism (ID 73, 199), maintenance of normal bone (ID 74), maintenance of normal teeth (ID 74), maintenance of normal hair (ID 74), maintenance of normal skin (ID 74), maintenance of normal nails (ID 74), contribution to normal energy-yielding metabolism (ID 75, 214), contribution to normal psychological functions (ID 77), reduction of tiredness and fatigue (ID 78), and contribution to normal cysteine synthesis (ID 4283) pursuant to Article 13(1) of Regulation (EC) No. 1924/2006. EFSA J 8, 1-35.

33. EFSA Panel on Dietetic Products NaAN (2010) Scientific opinion on the substantiation of health claims related to vitamin $\mathrm{C}$ and reduction of tiredness and fatigue (ID 139, 2622), contribution to normal psychological functions 
(ID 140), regeneration of the reduced form of vitamin $\mathrm{E}$ (ID 202), contribution to normal energy-yielding metabolism (ID 2334, 3196), maintenance of the normal function of the immune system (ID 4321) and protection of DNA, proteins and lipids from oxidative damage (ID 3331) pursuant to Article 13(1) of Regulation (EC) No. 1924/ 2006. EFSA J 8, 1-20.

34. Boon H, Hirschkorn K, Griener G, et al. (2009) The ethics of dietary supplements and natural health products in pharmacy practice: a systematic documentary analysis. Int J Pharm Pract 17, 31-38.

35. Satia-Abouta J, Kristal AR, Patterson RE, et al. (2003) Dietary supplement use and medical conditions: the VITAL study. Am J Prev Med 24, 43-51.

36. Murphy SP \& Poos MI (2002) Dietary reference intakes: summary of applications in dietary assessment. Public Health Nutr 5, 843-849.

37. Bailey RL, Fulgoni VLIII, et al. (2011) Dietary supplement use is associated with higher intakes of minerals from food sources. Am J Clin Nutr 94, 1376-1381.

38. Reinert A, Rohrmann S, Becker N, et al. (2007) Lifestyle and diet in people using dietary supplements. Eur J Nutr $\mathbf{4 6}$, $165-173$.

39. Mullie P, Clarys P, Hulens M, et al. (2011) Socioeconomic, health, and dietary determinants of multivitamin supplements use in Belgium. Int J Public Health 56, 289-294.

40. Jeon YJ, Myung SK, Lee EH, et al. (2011) Effects of betacarotene supplements on cancer prevention: meta-analysis of randomized controlled trials. Nutr Cancer 63, 1196-1207.

41. Ventola C (2010) Current issues regarding complementary and alternative medicine (CAM) in the United States. Pharma Therap 35, 461-468.
42. Tetens I, Biltoft-Jensen A, Spagner C, et al. (2011) Intake of micronutrients among Danish adult users and non-users of dietary supplements. Food Nutr Res $\mathbf{5 5}$ (Epublication ahead of print version 7 September 2011).

43. Shakur YA, Tarasuk V, Corey P, et al. (2012) A comparison of micronutrient inadequacy and risk of high micronutrient intakes among vitamin and mineral supplement users and nonusers in Canada. J Nutr 142, 534-540.

44. Palmer ME, Haller C, McKinney PE, et al. (2003) Adverse events associated with dietary supplements: an observational study. Lancet 361, 101-106.

45. Tsai HH, Lin HW, Simon Pickard A, et al. (2012) Evaluation of documented drug interactions and contraindications associated with herbs and dietary supplements: a systematic literature review. Int J Clin Pract 66, 1056-1078.

46. Hardy ML (2008) Dietary supplement use in cancer care: help or harm. Hematol Oncol Clin North Am 22, 581-617, vii.

47. Maillot M, Vieux F, Ferguson EF, et al. (2009) To meet nutrient recommendations, most French adults need to expand their habitual food repertoire. J Nutr 139, 1721-1727.

48. Agence bio CSA (2011) Baromètre de consommation et de perception des produits biologiques en France (Barometer of Consumption and Perception of Organic Products in France). Edition 2011.

49. Beitz R, Mensink GBM, Hintzpeter B, et al. (2004) Do users of dietary supplements differ from nonusers in their food consumption? Eur J Epidemiol 19, 335-341.

50. McNaughton SA, Mishra GD, Paul AA, et al. (2005) Supplement use is associated with health status and healthrelated behaviors in the 1946 British birth cohort. $J$ Nutr 135, 1782-1789. 